\title{
CLIMATOLOGIA DA FUNÇÃO FRONTOGENÉTICA SOBRE A AMÉRICA DO SUL EM UM CENÁRIO DE CLIMA PRESENTE E FUTURO
}

\author{
Diego Pedroso $^{1}$, Simone Erotildes Teleginski Ferraz ${ }^{1}$, Ernani de Lima Nascimento ${ }^{1}$, \\ Anderson Augusto Bier ${ }^{1}$, Marcelo Diaz ${ }^{1}$, Erikson Magno Gomes de Oliveira ${ }^{1}$, Rosmeri \\ Porfírio da Rocha², Tércio Ambrizzi ${ }^{2}$
}

${ }^{1}$ Universidade Federal de Santa Maria-CRS/INPE. Av. Roraima, $n^{\circ}$ 1000. Cidade Universitária - Santa Maria RS.

${ }^{2}$ Departamento de Ciências Atmosféricas do IAG/USP - Rua do Matão, 1226 - Cidade Universitária São Paulo $-\mathrm{SP}$.

\section{RESUMO}

Os campos climatológicos da Função Frontogenética de Petterssen (FF) foram calculados com a partir do modelo global HadGEM2-ES para uma série 1975-2005. Os primeiros resultados mostram-se concordantes com aqueles obtidos anteriormente por outros autores, indicando uma maior atividade de sistemas frontais durante o inverno e início da primavera. A partir destas constatações, a mesma metodologia pode ser utilizada com séries de clima futuro geradas pelo modelo.

\section{ABSTRACT}

Climatological fields of Petterssen's Frontogenetical Function (FF) were calculated from HadGEM2-ES global model for a time serie1975 to 2005. The first results show up in agreement with those obtained previously by other authors, indicating a higher activity of frontal systems during the winter and early spring. From these findings, the same methodology can be used with series of future climate generated by the model.

\section{INTRODUÇÃO}

As frentes são sistemas que atuam em escala sinótica, especialmente em latitudes médias, e são os principais agentes modificadores nas condições do tempo. Eles ocorrem ao longo de todo o ano, com maior intensidade no inverno, acompanhados de massas de ar polar que, muitas vezes, causam geadas sobre o Sul e Sudeste do Brasil. Algumas vezes, elas atingem latitudes mais baixas, chegando até a região Nordeste e sul da Amazônia causando o fenômeno conhecido como friagem (Cavalcanti, 2009).

Petterssen (1956) propôs um método objetivo para determinar locais preferenciais para formação (dissipação) de sistemas frontais utilizando agentes indicadores como gradiente de temperatura, orientação do eixo de dilatação, deformação total e divergência. Além disso, o principal agente causador da intensificação do gradiente horizontal de temperatura está associado à deformação no escoamento de baixos níveis.

Portanto, o objetivo principal desta pesquisa está concentrado em determinar uma climatologia da passagem de sistemas frontais sobre a América do Sul para uma série histórica e baseada nestes resultados, analisar as possíveis alterações neste regime sob um cenário de clima futuro. 


\section{DADOS E METODOLOGIA}

A base de dados na qual será investigada a ocorrência dos sistemas frontais utilizada neste estudo são oriundas do modelo HadGEM2-ES (Hadley Centre Global Environment Model version 2 - Earth System) tanto para o passado como para o futuro com uma resolução espacial de 150 x $150 \mathrm{~km}$.

A Função Frontogenética de Petterssen, daqui em diante denominada FF, é dada pela equação:

Sendo:

$$
F=\frac{1}{2}\left|\nabla \theta_{E}\right|(D \cos 2 \gamma-\delta)
$$

$\left|\nabla \theta_{E}\right|=$ módulo do grad. de temperatura potencial equivalente.

$D=\sqrt{D_{1}+D_{2}}$ deformação total.

$\gamma=$ orientação do eixo de dilatação.

$\delta=$ divergência.

A função frontogenética recebe valores positivos quando há condições para frontogênese, e negativo para frontólise. Nesta fase do estudo, será apresentada a análise para a série histórica da $\mathrm{FF}$ em $925 \mathrm{hPa}$, que conta com uma série mais longa, compreendendo um período de 30 anos (1975-2005), além de possuir uma melhor resolução espacial.

\section{RESULTADOS E DISCUSSÕES}

Os campos climatológicos obtidos para os meses representativos de cada estação do ano (verão, outono, inverno e primavera), mostrados na Figura 1. A região dos Andes mostra sucessões de atividade frontogenética e frontolítica em $925 \mathrm{hPa}$, porém esses resultados devem ser desconsiderados, uma vez que não são representativos.

Como mostrado por outros autores e também na observação sinótica de rotina, notase a atividade frontogenética aumentando na região sul e sudeste do Brasil no inverno diminuindo de intensidade nos meses de outono e primavera.

Nos meses de janeiro e abril, a atividade frontogenética sobre o sul do Brasil, na média, não é intensa. Observa-se, em janeiro, regiões de nenhuma ou com alguma atividade frontolítica (norte do RS e sobre o litoral da região Sudeste), indicando que os sistemas frontais que passam sobre a Argentina (onde há atividade frontal), perdem força e não atingem no sul do Brasil durante os meses de verão.

Durante os meses de inverno e primavera, a média da atividade frontogenética encontra-se atuante sobre o Sul do Brasil até parte da região Sudeste, indicando os locais preferenciais de passagens frontais.

Já sobre a Argentina entre as latitudes de $40^{\circ}$ e $55^{\circ} \mathrm{S}$, a atividade frontal permanece ativa durante todo o ano.
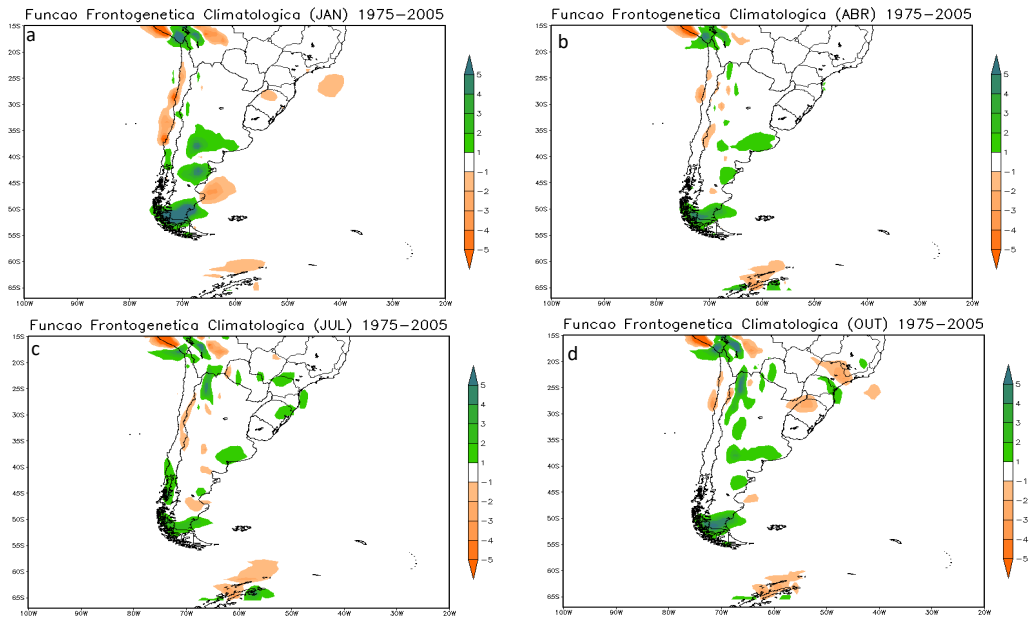


\section{CONCLUSÃO}

A distribuição espacial e temporal da Função Frontogenética de Petterssen foi calculada para mostrar a atividade frontal nos campos do modelo HadGEM2-ES. Além disso, confrontar resultados da mesma função com outros autores. De forma geral, o posicionamento e a magnitude dos campos concordam com trabalhos anteriores, tais como como de Satyamurty e Mattos (1989) e Mattos (2003). Desta forma, a FF pode ser estendida para análise no cenário futuro e.

Vale ressaltar que o modelo HadGEM2-ES serve como condição de contorno para as simulações regionais do modelo RegCM4.3. Assim, será possível avaliar a mudança no regime de temperatura e precipitação dessas regiões.

\section{REFERÊNCIAS BIBLIOGRÁFICAS}

CAVAlCAnTI, I. F. A. (Org.) Tempo e clima no Brasil. São Paulo: Oficina de Textos. 2009. 463pp.

MATTOS, L. F. Frontogênese na América do Sul e precursores de friagem no Estado de São Paulo. Tese de Doutorado. INPE São José dos Campos. 213p. 2003.

PETTERSEN, S. Weather Analysis and Forecasting. Vol.I McGraw-Hill, 428p. 1956.

SATYAMURTY P.; MATTOS L. F. Climatological lower tropospheric frontogenesis in the midlatitudes due to horizontal deformation and divergence. Mon. Wea. Rev., v. 117, n. 6, p. 1355-136. 1989. 